\title{
CYP79D enzymes contribute to jasmonic acid-induced formation of aldoximes and other nitrogenous volatiles in two Erythroxylum species
}

Katrin Luck ${ }^{1}$, Jan Jirschitzka ${ }^{1,2}$, Sandra Irmisch ${ }^{1,3}$, Meret Huber ${ }^{1}$, Jonathan Gershenzon ${ }^{1}$ and Tobias G. Köllner ${ }^{1 *}$

\begin{abstract}
Background: Amino acid-derived aldoximes and nitriles play important roles in plant defence. They are well-known as precursors for constitutive defence compounds such as cyanogenic glucosides and glucosinolates, but are also released as volatiles after insect feeding. Cytochrome P450 monooxygenases (CYP) of the CYP79 family catalyze the formation of aldoximes from the corresponding amino acids. However, the majority of CYP79s characterized so far are involved in cyanogenic glucoside or glucosinolate biosynthesis and only a few have been reported to be responsible for nitrogenous volatile production.
\end{abstract}

Results: In this study we analysed and compared the jasmonic acid-induced volatile blends of two Erythroxylum species, the cultivated South American crop species E. coca and the African wild species E. fischeri. Both species produced different nitrogenous compounds including aliphatic aldoximes and an aromatic nitrile. Four isolated CYP79 genes (two from each species) were heterologously expressed in yeast and biochemically characterized. CYP79D62 from E. coca and CYP79D61 and CYP79D60 from E. fischeri showed broad substrate specificity in vitro and converted L-phenylalanine, L-isoleucine, L-leucine, L-tryptophan, and L-tyrosine into the respective aldoximes. In contrast, recombinant CYP79D63 from E. coca exclusively accepted L-tryptophan as substrate. Quantitative real-time PCR revealed that CYP79D60, CYP79D61, and CYP79D62 were significantly upregulated in jasmonic acid-treated Erythroxylum leaves.

Conclusions: The kinetic parameters of the enzymes expressed in vitro coupled with the expression patterns of the corresponding genes and the accumulation and emission of (E/Z)-phenylacetaldoxime, (E/Z)-indole-3-acetaldoxime, (E/Z)-3-methylbutyraldoxime, and (E/Z)-2-methylbutyraldoxime in jasmonic acid-treated leaves suggest that CYP79D60, CYP79D61, and CYP79D62 accept L-phenylalanine, L-leucine, L-isoleucine, and L-tryptophan as substrates in vivo and contribute to the production of volatile and semi-volatile nitrogenous defence compounds in E. coca and E. fischeri.

Keywords: Erythroxylum, Cytochrome P450 monooxygenase, CYP79, Aldoxime, Volatiles

\section{Background}

Plant volatiles play diverse roles in the interactions between plants and their environment. Flower volatiles, for example, can attract pollinators while vegetative volatiles are involved in plant defence, either directly by repelling the attacker or indirectly by e.g. attracting herbivore enemies $[1-5]$. The formation and emission of vegetative

\footnotetext{
*Correspondence: koellner@ice.mpg.de

${ }^{1}$ Max Planck Institute for Chemical Ecology, Hans-Knöll-Strasse 8, D-07745

Jena, Germany

Full list of author information is available at the end of the article
}

volatiles is often induced by chewing or sucking herbivores and the resulting volatile blends usually contain dozens of substances from diverse classes of natural compounds [6-9]. Herbivore-induced volatile blends are in general dominated by terpenes and green leaf volatiles (GLVs, $\mathrm{C}_{6}$ aldehydes, alcohols and esters derived from fatty acid cleavage), but comprise also aromatic compounds, alcohols, and nitrogen-containing amino acid derivatives [10]. While the formation and biological roles of terpenes and GLVs have been extensively studied in the 
past, our knowledge about the other components of herbivore-induced volatile blends is still limited.

Nitrogen-containing vegetative volatiles such as aldoximes, nitriles and nitro compounds are widely distributed among the angiosperms and have been reported from e.g. the Salicaceae, Fabaceae, Solanaceae, Cucurbitaceae, Rutaceae, Rosaceae, and Poaceae [11]. Poplars (Salicaceae), for example, release a complex mixture of aliphatic aldoximes, aliphatic and aromatic nitriles, and an aromatic nitro compound in response to herbivory by gypsy moth (Lymantria dispar) larvae [7, 11, 12]. Although these nitrogen-containing volatiles are minor components of the total blend, they likely play important roles in indirect and direct poplar defence. Electrophysiological recordings and olfactometer bioassays revealed that volatile aldoximes were more attractive for a gypsy moth parasitoid than the major terpenes and GLVs [12]. Moreover, poplar nitriles were shown to be repellent for gypsy moth caterpillars, while volatile and semi-volatile aldoximes had toxic effects on these larvae $[11,13]$.

Aldoximes and nitriles are produced from amino acids through the action of cytochrome P450 monooxygenases (CYP) of the CYP79 and CYP71/736 families (recently reviewed in [14]). CYP79 enzymes accept amino acids as substrates and catalyse the formation of aldoximes by two successive $N$-hydroxylations, a dehydration and a decarboxylation reaction $[15,16]$. The aldoximes formed can then serve as substrates for CYP71 enzymes, which convert them into the corresponding nitriles [13]. The first characterized CYP79 enzyme, CYP79A1 from Sorghum bicolor, was identified and characterized in 1995 by Sibbesen and co-workers [16]. It catalyses the reaction from L-tyrosine to $p$-hydroxyphenylacetaldoxime, which is further converted into the cyanogenic glucoside dhurrin in sorghum [16]. While most of the CYP79 enzymes characterized so far produce aldoximes as precursors for cyanogenic glucosides, glucosinolates, and other non-volatile nitrogen-containing defence compounds, a few CYP79s from two different poplar species (CYP79D6v3 and CYP79D7v2 from Populus trichocarpa and CYP79D6v4 from P. nigra) have been reported to be responsible for herbivore-induced volatile production $[11,12,17]$. CYP79s involved in cyanogenic glucoside and glucosinolate formation usually possess high substrate specificity, thus determining the specificity of the entire pathway [18-21]. In contrast, poplar CYP79D6 and CYP79D7 have broader substrate specificity and produce complex mixtures of volatile and semi-volatile aldoximes [11, 12, 17].

To expand our knowledge about the formation of volatile aldoximes and nitriles, we have now begun to investigate and compare their biosynthesis in the genus Erythroxylum. Two species with different geographical origins and cultivation histories were chosen for this analysis. Erythroxylum coca is an economically and pharmacologically important crop cultivated on the eastern slopes of the Andes since more than 8000 years. $E$. fischerii, in contrast, is a wild species native to the tropical forests in Africa. Both species are members of the Erythroxylaceae, which belong, like poplars, to the diverse order Malpighiales. Since it has been shown that the formation of volatiles can be induced by artificial treatments with the plant hormone jasmonic acid (JA) (e.g. $[12,22])$, we measured and compared volatile emission in response to JA treatment in $E$. coca and $E$. fischeri and detected numerous nitrogen-containing compounds. Candidate CYP79 genes isolated from both species were then heterologously expressed in yeast, and enzyme characterization and gene expression analysis indicated a potential function of individual Erythroxylum CYP79 proteins in volatile aldoxime formation.

\section{Results \\ Jasmonic acid induces the emission of nitrogenous volatiles in Erythroxylum coca and E. fischeri}

Many plant species respond to herbivory with an increased JA accumulation that induces the biosynthesis of diverse plant defence compounds including nitrogencontaining volatiles [23]. Hence to study the formation of nitrogenous volatiles in Erythroxylum species, we collected and compared the volatile blends of untreated and JAtreated twigs of E. coca and E. fischeri. Although both species emitted volatiles from untreated twigs, JA-treatment significantly increased volatile emission (Table 1). The blends from control and JA-treated twigs of E. coca and $E$. fischeri were dominated by monoterpenes (e.g. $(E)$ - $\beta$-ocimene, mentha-1,5,8-triene, and linalool), sesquiterpenes (e.g. $\beta$-elemene and $(E, E)$ - $\alpha$-farnesene) and the homoterpenes (3E)-4,8-dimethylnona-1,3,7-triene (DMNT) and (3E,7E)-4,8,12-trimethyltrideca-1,3,7,11-tetraene (TMTT). In addition, both species produced significant amounts of nitrogenous volatiles such as $(E / Z)$-2-methylbutyraldoxime, (E/Z)-3-methylbutyraldoxime, benzyl cyanide, phenylnitroethane, an unidentified nitro compound, and indole in response to JA treatment (Table 1). As typical herbivoreinduced vegetative volatiles, green leaf volatiles were also present in JA-induced E. coca and E. fischeri blends. Notably, the qualitative compositions of the JA-induced volatile blends of both species were nearly identical and the total amounts of released volatiles were in the same range. However, there were major quantitative differences in the emission of single volatiles between E. coca and E. fischeri (Table 1). While $E$. coca, for instance, emitted $\beta$-elemene as major sesquiterpene and produced minor amounts of $(E, E)$ - $\alpha$-farnesene, $E$. fischerii released large amounts of $(E, E)$ - $\alpha$-farnesene and produced only traces of $\beta$-elemene. Another remarkable difference was found for indole, which 
Table 1 Volatile compounds of Erythroxylum coca and E. fischeri released from untreated twigs (control) and jasmonic acid-treated twigs (JA treatment)

\begin{tabular}{|c|c|c|c|c|c|c|}
\hline \multirow{3}{*}{ Compound } & \multicolumn{3}{|c|}{ Erythroxylum coca } & \multicolumn{3}{|c|}{ Erythroxylum fischeri } \\
\hline & Control & JA treatment & $P$-value & Control & JA treatment & $P$-value \\
\hline & (Mean $\pm \mathrm{SE})$ & (Mean \pm SE) & & (Mean $\pm \mathrm{SE})$ & $($ Mean \pm SE) & \\
\hline \multicolumn{7}{|l|}{$\mathrm{N}$-containing volatiles } \\
\hline (E)-3-methylbutyraldoxime* & $0.6 \pm 0.4$ & $40.1 \pm 9.6$ & 0.020 & $0+0$ & $23.7+7.4$ & 0.037 \\
\hline (E)-2-methylbutyraldoxime* & $0.4 \pm 0.4$ & $51.5 \pm 9.7$ & 0.018 & $0+0$ & $16.1+10.6$ & 0.037 \\
\hline (Z)-2-methylbutyraldoxime* & $0.2 \pm 0.2$ & $9.5 \pm 2.2$ & 0.018 & $0+0$ & $4.4+1.3$ & 0.037 \\
\hline (Z)-3-methylbutyraldoxime* & $0 \pm 0$ & $29.7 \pm 6.6$ & 0.014 & $0+0$ & $17.1+7.2$ & 0.037 \\
\hline benzyl cyanide* & $0.1 \pm 0.1$ & $315.6 \pm 76.5$ & 0.018 & $2.1+1.2$ & $241+199.7$ & 0.050 \\
\hline phenylnitroethane & $3.7 \pm 0.7$ & $99 \pm 26.4$ & 0.021 & $7.7+4.6$ & $62.4+39.8$ & 0.050 \\
\hline unidentified nitro compound & $0.1 \pm 0.1$ & $3.1 \pm 0.9$ & 0.018 & $0.8+0.8$ & $21+11.8$ & 0.046 \\
\hline indole* & $4.5 \pm 2$ & $256.2 \pm 50.3$ & 0.021 & $2.1+1$ & $13.2+2.3$ & 0.050 \\
\hline \multicolumn{7}{|l|}{ monoterpenoids } \\
\hline myrcene* & $4.7 \pm 0.8$ & $29.2 \pm 3.5$ & 0.021 & $5.7+1.8$ & $36.1+4.7$ & 0.050 \\
\hline (Z)-ocimene* & $4.2 \pm 0.5$ & $107.7 \pm 19.9$ & 0.021 & $4.2+1.5$ & $83.4+9.8$ & 0.050 \\
\hline (E)-ocimene* & $289.1 \pm 54.1$ & $14685.7 \pm 4017.2$ & 0.021 & $281.3+105.8$ & $9257+847.3$ & 0.050 \\
\hline allo-ocimene & $0 \pm 0$ & $15.6 \pm 2$ & 0.014 & $0+0$ & $1.7+0.4$ & 0.037 \\
\hline mentha-1,5,8-triene & $1.1 \pm 0.2$ & $25.6 \pm 3.3$ & 0.021 & $10.7+6.2$ & $572.7+252.6$ & 0.050 \\
\hline (Z)-linalool oxide & $6.7 \pm 1.6$ & $130.7 \pm 30.8$ & 0.021 & $2.6+0.9$ & $16.8+3$ & 0.050 \\
\hline (E)-epoxy-ocimene & $3.5 \pm 0.6$ & $780.2 \pm 152.6$ & 0.021 & $1.4+0.4$ & $105.6+43.6$ & 0.050 \\
\hline linaloo * & $64.4 \pm 20.1$ & $1709.8 \pm 555.1$ & 0.021 & $56+23.3$ & $178.6+16.8$ & 0.050 \\
\hline unidentified monoterpene 1 & $0 \pm 0$ & $6.5 \pm 0.7$ & 0.014 & $0.9+0.4$ & $19.8+6.6$ & 0.050 \\
\hline unidentified monoterpene oxide 1 & $0.1 \pm 0.1$ & $9 \pm 1.9$ & 0.018 & $0+0$ & $1.9+1.4$ & 0.121 \\
\hline unidentified monoterpene oxide 2 & $0.3 \pm 0.2$ & $11.5 \pm 1.9$ & 0.020 & $0+0$ & $6+0.3$ & 0.037 \\
\hline \multicolumn{7}{|l|}{ sesquiterpenoids } \\
\hline$\beta$-elemene* & $133.6 \pm 32.4$ & $208.2 \pm 48.7$ & 0.248 & $0+0$ & $1+0$ & 0.037 \\
\hline (E)- $\beta$-caryophyllene* & $79.4 \pm 17.1$ & $72.9 \pm 9.8$ & 0.564 & $0.2+0.2$ & $5.3+0.3$ & 0.046 \\
\hline$(Z, E)$-a-farnesene & $1.8 \pm 1.8$ & $16.2 \pm 2.6$ & 0.018 & $0+0$ & $3.1+1.5$ & 0.037 \\
\hline$(E, E)$-a-farnesene & $17.5 \pm 5.2$ & $76.5 \pm 14.6$ & 0.021 & $240.4+176.9$ & $1505.1+698.4$ & 0.127 \\
\hline unidentified sesquiterpene 1 & $10.7 \pm 4.9$ & $26.6 \pm 3.8$ & 0.083 & $0.6+0.3$ & $6.4+0.6$ & 0.050 \\
\hline unidentified sesquiterpene 2 & $9.8 \pm 4.4$ & $20.9 \pm 2.8$ & 0.083 & $0.1+0.1$ & $3.3+0.3$ & 0.046 \\
\hline unidentified sesquiterpene 3 & $13.6 \pm 5.8$ & $24.7 \pm 3.7$ & 0.083 & $0+0$ & $0.3+0.3$ & 0.317 \\
\hline unidentified sesquiterpene 4 & $12.8 \pm 7.5$ & $46.5 \pm 13.5$ & 0.083 & $8.8+6.3$ & $42.2+14.9$ & 0.127 \\
\hline unidentified sesquiterpene 5 & $4.1 \pm 2.4$ & $19.8 \pm 4.5$ & 0.042 & $0.5+0.3$ & $1.4+0.2$ & 0.050 \\
\hline unidentified sesquiterpene 6 & $12 \pm 3.3$ & $23.6 \pm 4$ & 0.043 & $0+0$ & $0.6+0.6$ & 0.317 \\
\hline \multicolumn{7}{|l|}{ homoterpenes } \\
\hline $\mathrm{DMNT}^{*}$ & $91.2 \pm 20.2$ & $112.1 \pm 25.7$ & 0.773 & $14.8+6.3$ & $51.6+25.4$ & 0.127 \\
\hline TMTT* & $524.6 \pm 138.9$ & $1009.9 \pm 218.1$ & 0.043 & $187.6+91.2$ & $630.5+159.4$ & 0.050 \\
\hline \multicolumn{7}{|l|}{ diterpenes } \\
\hline geranyl linalool* & $3.8 \pm 1$ & $19.2 \pm 3.9$ & 0.021 & $0+0$ & $0+0$ & NA \\
\hline \multicolumn{7}{|l|}{ GLVs and ester } \\
\hline (Z)-3-hexenyl acetate* & $9.5 \pm 3.8$ & $15.7 \pm 2.6$ & 0.149 & $4.6+2.3$ & $80.5+32.6$ & 0.050 \\
\hline (E)-2-hexenyl acetate & $0 \pm 0$ & $0 \pm 0$ & NA & $4.6+1$ & $21.3+9$ & 0.275 \\
\hline (Z)-3-hexenol* & $0.1 \pm 0.1$ & $0 \pm 0$ & 0.317 & $0+0$ & $11.3+0.3$ & 0.037 \\
\hline
\end{tabular}


Table 1 Volatile compounds of Erythroxylum coca and E. fischeri released from untreated twigs (control) and jasmonic acid-treated twigs (JA treatment) (Continued)

\begin{tabular}{|c|c|c|c|c|c|c|}
\hline (Z)-3-hexenyl propionate & $13.1 \pm 3.1$ & $81.5 \pm 14.8$ & 0.021 & $1.9+0.6$ & $14.8+7.9$ & 0.050 \\
\hline (Z)-3-hexenyl isobutyrate & $2.3 \pm 0.2$ & $91.5 \pm 17.5$ & 0.014 & $2.5+0.5$ & $55+14.2$ & 0.037 \\
\hline (Z)-3-hexenyl 2-methylbutanoate & $0 \pm 0$ & $65.2 \pm 24.7$ & 0.047 & $0+0$ & $8.2+4.5$ & 0.121 \\
\hline (E)-3-hexenyl hexanoate & $2.2 \pm 0.5$ & $36.7 \pm 5.7$ & 0.021 & $0.7+0.2$ & $4.7+0.9$ & 0.050 \\
\hline (Z)-3-hexenyl tiglate & $35.4 \pm 8.2$ & $132.3 \pm 18.1$ & 0.021 & $1.2+0.3$ & $6.2+1.5$ & 0.050 \\
\hline unidentified ester & $0 \pm 0$ & $6.1 \pm 1$ & 0.021 & $0+0$ & $1.8+0.2$ & 0.050 \\
\hline \multicolumn{7}{|l|}{ alcohols } \\
\hline benzyl alcohol* & $4.9 \pm 1.4$ & $53.1 \pm 7$ & 0.021 & $0.1+0.1$ & $3.4+3.1$ & 0.246 \\
\hline 2-phenylethanol* & $1.3 \pm 0.3$ & $104.3 \pm 24.2$ & 0.021 & $1+0.8$ & $36.4+33.9$ & 0.127 \\
\hline \multicolumn{7}{|l|}{ unidentified compounds } \\
\hline unidentified compound 1 & $3.6 \pm 0.7$ & $39.5 \pm 4.5$ & 0.021 & $3.1+1.1$ & $40.2+5.5$ & 0.050 \\
\hline unidentified compound 2 & $0 \pm 0$ & $24 \pm 4.6$ & 0.014 & $0+0$ & $5.5+2.1$ & 0.037 \\
\hline unidentified compound 3 & $3.8 \pm 0.6$ & $35.7 \pm 6.8$ & 0.021 & $2.6+0.8$ & $32.9+12.7$ & 0.050 \\
\hline unidentified compound 4 & $0.1 \pm 0.1$ & $16.7 \pm 3.2$ & 0.018 & $0+0$ & $14.7+5.9$ & 0.037 \\
\hline unidentified compound 5 & $1.4 \pm 0.9$ & $31.4 \pm 9.7$ & 0.020 & $0+0$ & $0+0$ & NA \\
\hline unidentified compound 6 & $1.3 \pm 1.3$ & $85 \pm 22.8$ & 0.018 & $0+0$ & $1.8+0.3$ & 0.037 \\
\hline unidentified compound 7 & $56.4 \pm 12.5$ & $71 \pm 7.2$ & 0.386 & $21+10.7$ & $41+12.1$ & 0.275 \\
\hline unidentified compound 8 & $0 \pm 0$ & $12.9 \pm 2.3$ & 0.014 & $0+0$ & $2.9+0.7$ & 0.037 \\
\hline unidentified compound 9 & $0.5 \pm 0.2$ & $10.1 \pm 1.1$ & 0.021 & $0.5+0.3$ & $9.7+1.7$ & 0.050 \\
\hline unidentified compound 10 & $0.5 \pm 0.2$ & $18.8 \pm 0.9$ & 0.021 & $0.6+0.4$ & $9.5+0.3$ & 0.050 \\
\hline unidentified compound 11 & $1.9 \pm 0.3$ & $13.8 \pm 0.6$ & 0.021 & $0.6+0.2$ & $7.2+0.8$ & 0.050 \\
\hline unidentified compound 12 & $0 \pm 0$ & $10.7 \pm 0.4$ & 0.014 & $0+0$ & $5.2+0.5$ & 0.037 \\
\hline unidentified compound 13 & $0 \pm 0$ & $27.6 \pm 5.6$ & 0.014 & $0+0$ & $7.1+7.1$ & 0.317 \\
\hline total volatiles & $1508 \pm 322$ & $21101 \pm 4605$ & 0.021 & $874 \pm 402$ & $13351 \pm 458$ & 0.050 \\
\hline
\end{tabular}

Emission rates are displayed as means $\pm \mathrm{SE}$ in $\mathrm{ng} \mathrm{g}^{-1}$ fresh weight $\mathrm{h}^{-1}(E$. coca, $n=4$; E. fischeri, $n=3$ ). $P$-values are based on the results from Kruskal-Wallis rank sum tests between the control and the JA-treatment. $P$-values $\leq 0.05$ indicate significant differences and are shown in bold. Compounds identified using authentic standards are marked with asterisks $(*)$. Unmarked compounds were identified by comparison of their mass spectra with those of reference libraries

was one of the dominant nitrogen-containing volatiles in $E$. coca but was a minor compound in E. fischeri.

\section{Identification of CYP79 enzymes from $E$. coca and $E$. fischeri}

To identify putative Erythroxylum CYP79 genes, a TBLASTN search against an in-house 454 cDNA sequencing database of $E$. coca young leaf tissue [24, 25] was conducted using the amino acid sequence of CYP79D6v3 from Populus trichocarpa [11] as input sequence. One sequence representing a putative P450 enzyme of the CYP79 family was identified. Amplification of this gene resulted in two highly homologous sequences that were designated as CYP79D62 and CYP79D63 according to the general P450 nomenclature (D.R. Nelson, P450 Nomenclature Committee). PCR with cDNA made from JA-treated $E$. fischeri leaves using the primer pair designed for amplification of $E$. coca sequences revealed an additional gene (CYP79D60). To identify further potential CYP79D candidates, primers specific to conserved regions among the obtained genes were designed and PCR was performed with CDNA made from JA-treated Erythroxylum leaves. While most of the resulting amplicons were identical to CYP79D62, CYP79D63, and CYP79D60, one fragment amplified from $E$. fischeri cDNA showed sequence divergence and the isolated full-length clone was designated as CYP79D61.

Motifs reported to be conserved in nearly all P450 enzymes, such as the ProProxxPro motif at the Nterminus, the heme binding site ProPheGlyxGlyArgArgxCysxGly, and the ProGluArgPhe motif, could be identified in the obtained Erythroxylum CYP79 sequences (Fig. 1). In comparison to the general P450 consensus sequences [26], Erythroxylum CYP79 motifs showed substitutions characteristic for the CYP79 family. Moreover, a CYP79-specific AsnPro motif in one of the proposed substrate binding sites [26] was also found in the Erythroxylum sequences (Fig. 1). A dendrogram analysis showed that Erythroxylum CYP79 enzymes 


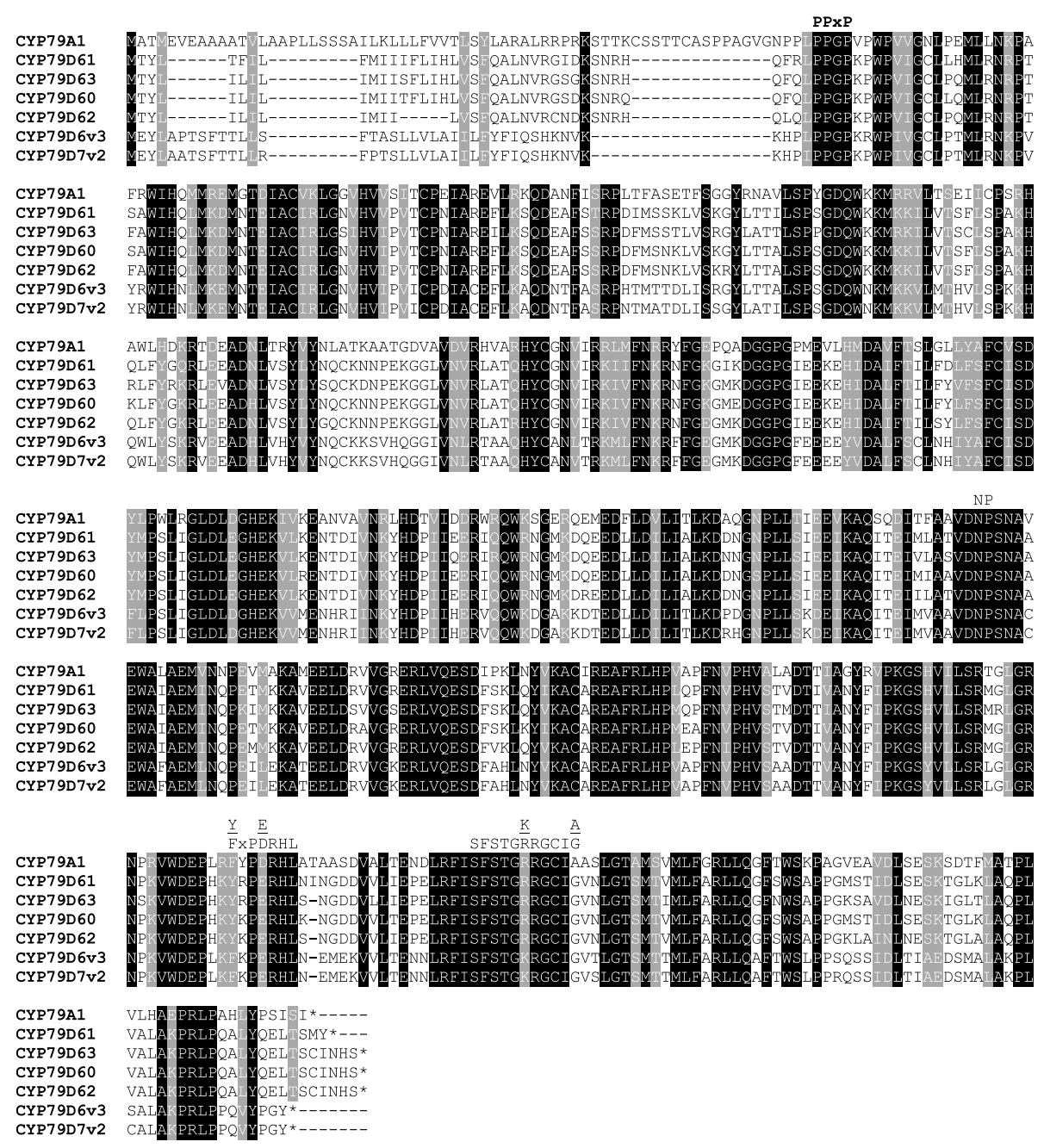

Fig. 1 Amino acid sequence alignment of Erythroxylum CYP79s with CYP79A1 from Sorghum bicolor and CYP79D6v3 and CYP79D7v2 from Populus trichocarpa. Black boxes mark conserved residues and grey boxes mark residues with similar physicochemical properties. The conserved motifs are labeled and 'NP' indicates the exchange of the generally conserved CYP motif, Thr-(Thr/Ser), with the Asn-Pro motif typical of the CYP79 family

grouped together with CYP79D6v3, CYP79D7v2, and CYP79D6v4 from poplar and CYP79D enzymes from other plants (Fig. 2).

To test the enzymatic activity of the identified Erythroxylum CYP79s, genes were heterologously expressed in Saccharomyces cerevisiae $\left(\mathrm{WAT}_{11}\right)$ and microsomes harbouring recombinant protein were incubated with the potential amino acid substrates L-phenylalanine, L-tyrosine, L-tryptophan, L-leucine, and L-isoleucine in the presence of NADPH as cosubstrate. CYP79D63 showed narrow substrate specificity and was only able to accept tryptophan as substrate, converting it into $(E / Z)$-indole-3-acetaldoxime (Fig. 3). In contrast, CYP79D62, CYP79D60, and CYP79D61 accepted all tested amino acids and produced (E/Z)-phenylacetaldoxime, (E/Z)-p-hydroxyphenylacetaldoxime, (E/Z)-indole-3-acetaldoxime, (E/Z)-3-methylbutyraldoxime, and (E/Z)-2-methylbutyraldoxime, respectively, from the amino acids listed above (Figs. 3 and 4). Assays using microsomes from yeast cells expressing the empty vector, assays without NADPH and assays with boiled proteins showed no activity (data not shown).

$K_{\mathrm{m}}$ values for the different substrates of CYP79D60, CYP79D62, and CYP79D63 are given in Table 2. Since measurements of carbon monoxide difference spectra failed, we were not able to determine the protein concentrations in the microsomes and thus to calculate the turnover numbers for the different substrates. Instead, the relative product formation with $1 \mathrm{mM}$ of the respective amino acid substrate was measured (Table 2). For CYP79D60 and CYP79D62, the combination of relatively low $K_{\mathrm{m}}$ values for L-Phe and L-Leu combined with a high rate of product formation suggest that these amino acids are the preferred substrates in planta. Although CYP79D63, which only accepted L-Trp 


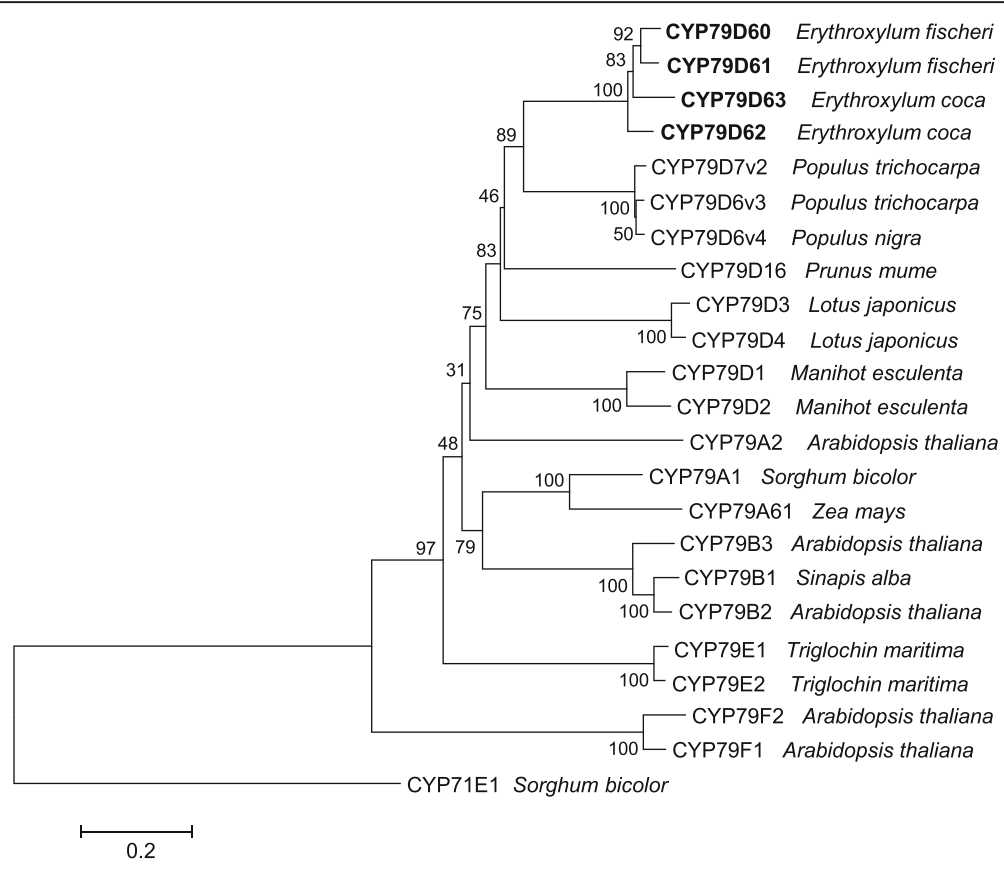

Fig. 2 Rooted phylogenetic tree of Erythroxylum CYP79D proteins and characterized CYP79 proteins from other plants. The tree was inferred by using the neighbor joining method and $n=1000$ replicates for bootstrapping. Bootstrap values are shown next to each node. CYP71E1 was used as the outgroup. The tree is drawn to scale, with branch lengths measured in the number of substitutions per site. Enzymes described in this study are shown in bold. Accession numbers: CYP71E1, AF029858.1; CYP79F1, NM_101507.2; CYP79F2, AF275259.1; CYP79B2, NM_120158.2; CYP79B1, AF069494.1; CYP79B3, NM_127798.3; CYP79A61, KP297890.1; CYP79A1, U32624.1; CYP79D2, AY834390.1; CYP79D1, AY834391.1; CYP79E2, AF140610.1; CYP79E1, AF140609.1; CYP79A2, AF245302.1; CYP79D4, AY599896.1; CYP79D3, AY599895.1; CYP79D16, AB920488.1; CYP79D7v2, KF562516.1; CYP79D6V3, KF562515.1; CYP79D6v4, KF870998.1

as a substrate, had a lower $K_{\mathrm{m}}$ value for this amino acid than CYP79D60 and CYP79D61 $(0.48 \pm 0.05 \mathrm{mM}$ versus $2.74 \pm 0.11 \mathrm{mM}$ and $1.09 \pm 0.04 \mathrm{mM}$, respectively), the rate of product formation indicates a low turn-over number for this enzyme.

\section{Gene expression analysis of Erythroxylum CYP79 genes}

Quantitative real-time PCR (qRT-PCR) was used to compare transcript accumulation of CYP79 genes between untreated and JA-treated twigs in E. coca and $E$. fischeri. To identify reference genes with stable expression under our experimental conditions, we analysed transcript accumulation of a set of nine potential $E$. coca qRT-PCR reference genes [27] in untreated and JAtreated leaves of E. coca and E. fischeri (Additional file 1: Tables S1 and S2). Expressed protein Ec6409 and the clathrin adaptor complex subunit Ec11142 were chosen as reference genes for qRT-PCR analysis of CYP79 genes in E. coca and E. fischeri, respectively, based on their low $\mathrm{Ct}$ value variability between the different treatments (Additional file 1: Tables S1 and S2). In E. coca, CYP79D62 showed a significantly upregulated gene expression in JA-treated twigs in comparison to untreated controls (Fig. 5a). In contrast, transcript accumulation of CYP79D63 was not influenced by the treatment (Fig. 5a).
In E. fischeri, CYP79D60 and CYP79D61 were both significantly upregulated after JA treatment (Fig. $5 \mathrm{~b}$ ), but the average $\mathrm{Cq}$ value for CYP79D61 was higher than the average Cq value for CYP79D60 in JA-treated leaves (27.4 versus 20.5), suggesting higher gene expression for CYP79D60 in comparison to CYP79D61 after JA treatment.

Accumulation of aldoximes, indole-3-acetic acid, and amino acids in JA-treated Erythroxylum plants

To test whether CYP79 products accumulate in JAtreated and untreated leaves of E. coca and E. fischeri, we analysed leaf methanol extracts using liquid chromatography-tandem mass spectrometry. (E/Z)Phenylacetaldoxime, $(E / Z)$-indole-3-acetaldoxime, $(E / Z)$ 2-methylbutyraldoxime, and (E/Z)-3-methylbutyraldoxime showed significantly increased accumulation in both species after JA-treatment in comparison to untreated controls (Fig. 6). Only trace amounts of these aldoximes could be detected in untreated leaves. Notably, the induced accumulation of (E/Z)-2-methylbutyraldoxime and (E/Z)-3-methylbutyraldoxime corresponded well with the emission of these compounds from JA-treated leaves (Table 1). The absence of the aromatic aldoximes $(E / Z)$-phenylacetaldoxime and $(E / Z)$-indole-3-acetaldoxime in the volatile blends (Table 1 ) is most likely due to 
CYP79D62

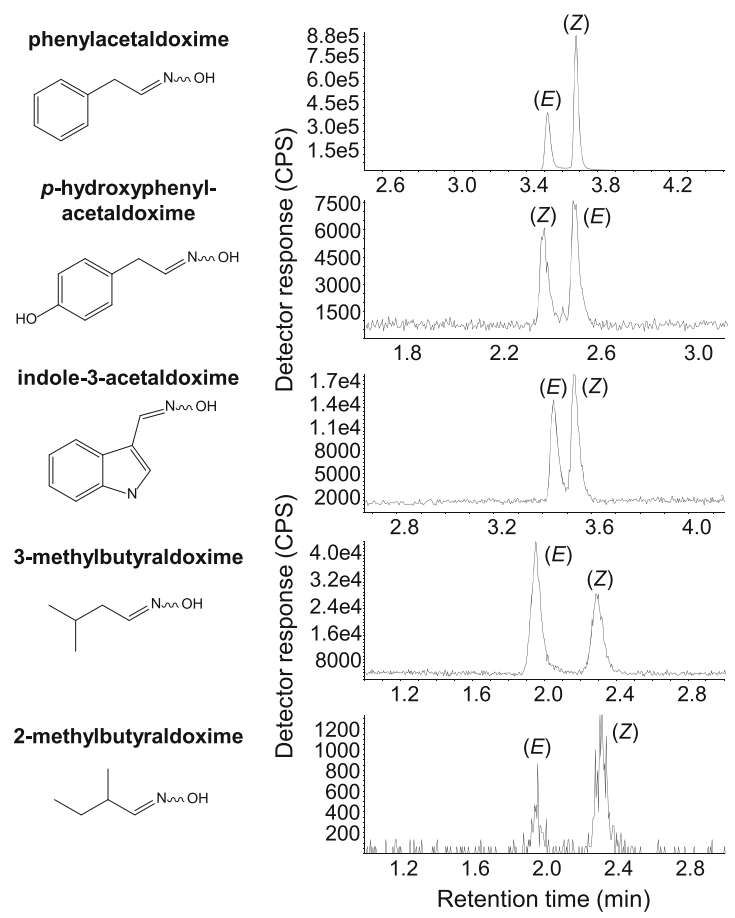

CYP79D63

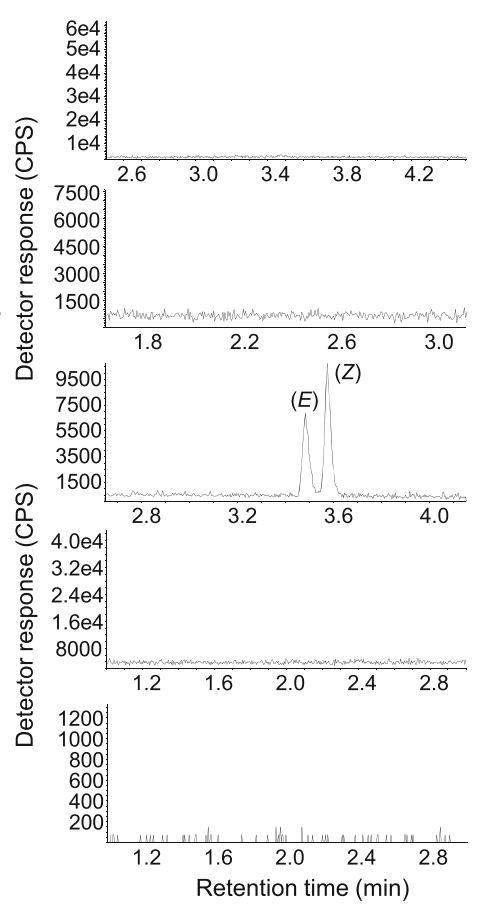

Fig. 3 Biochemical characterization of Erythroxylum coca CYP79D62 and CYP79D63. The genes were heterologously expressed in Saccharomyces cerevisae and microsome preparations containing the recombinant proteins were incubated with the potential amino acid substrates L-Phe, L-Tyr, L-Trp, L-Leu, and L-lle. The respective reaction products of each substrate are depicted sequentially next to their LC-MS/MS traces

their low volatility in comparison to the aliphatic aldoximes. In contrast to the aldoximes, indole-3acetic acid (IAA), a potential conversion product of $(E / Z)$-indole-3-acetaldoxime, was constitutively produced in untreated and JA-treated leaves of both $E$. coca and E. fischeri (Fig. 6).

The analysis of amino acids as potential CYP79 substrates in JA-treated leaves vs. untreated control leaves revealed a significant induction for L-Ala, L-Val, L-Thr, L-Leu, L-Ile, L-His, L-Phe, L-Trp, and L-Tyr in E. coca and for L-Ala, L-Asp, and L-Gln in E. fischeri (Additional file 1: Table S3).

\section{Discussion}

The production of volatiles in response to insect herbivory appears to be a widespread part of plant defence. Herbivore-induced volatiles can influence the feeding or oviposition behaviour of herbivores and are described to attract herbivore enemies such as parasitic wasps, predatory arthropods, and insectivorous birds [1]. Jasmonic acid, a phytohormone known to be involved in several physiological processes, plays an important role in triggering different plant defence reactions including volatile formation $[23,28,29]$. Thus, pure JA or its derivatives and mimics are often used as artificial elicitors for the induction of vegetative volatile emission
$[22,30,31]$. In this study we showed that JA also induced the emission of complex volatile blends in $E$. coca and $E$. fischeri. The blends were dominated by terpenes and GLVs, but also possessed nitrogen-containing compounds such as the nitrile benzyl cyanide, phenylnitroethane, and some aliphatic aldoximes (Table 1). The roles of herbivore-induced nitrogenous volatiles in direct and indirect plant defense have recently been investigated in poplar. Olfactometer experiments showed that benzyl cyanide and two other volatile nitriles had a strong repellant activity against gypsy moth caterpillars, a generalist herbivore known to feed on poplar [13]. Volatile aliphatic aldoximes were found to be attractive for a parasitoid of gypsy moth larvae in laboratory as well as field experiments [12], and the semi-volatile (E,Z)-phenylacetaldoxime, which accumulated after herbivory in poplar leaves, decreased survival and weight gain of gypsy moth larvae in feeding experiments [11]. Since in the present study volatile aliphatic and aromatic aldoximes, nitriles and nitro compounds and the semi volatile $(E, Z)$-phenylacetaldoxime were found to be emitted from or accumulated in the two investigated Erythroxylum species after treatment with JA in the same order of magnitude as that previously reported for herbivore-damaged poplar leaves [11-13], these compounds might play similar roles in plant defence against natural Erythroxylum herbivores such 


\section{CYP79D60}

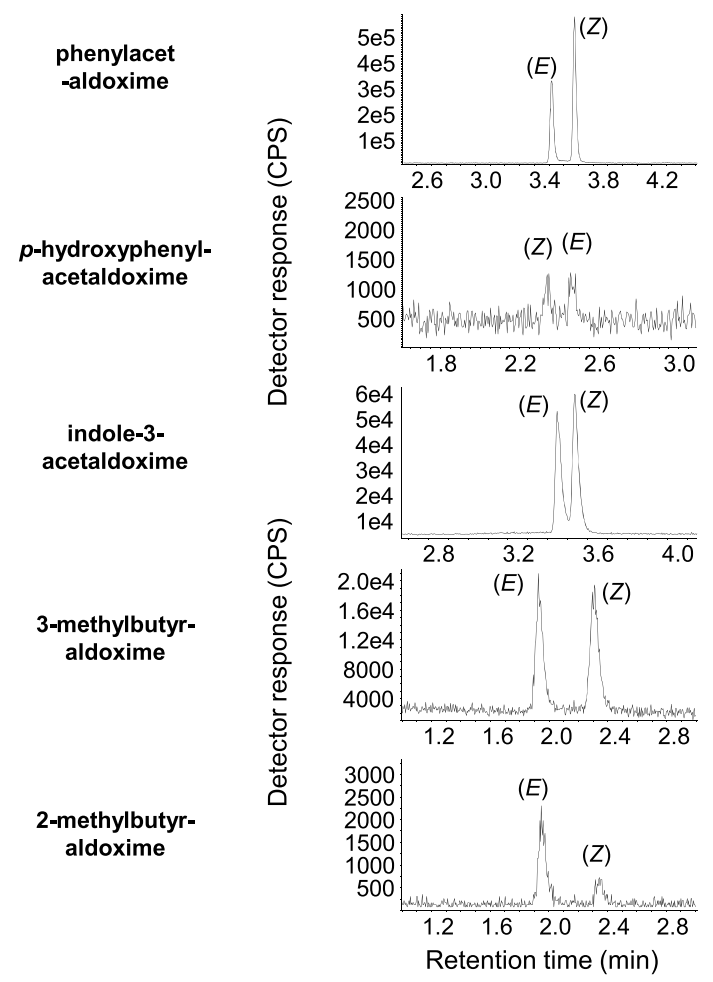

CYP79D61

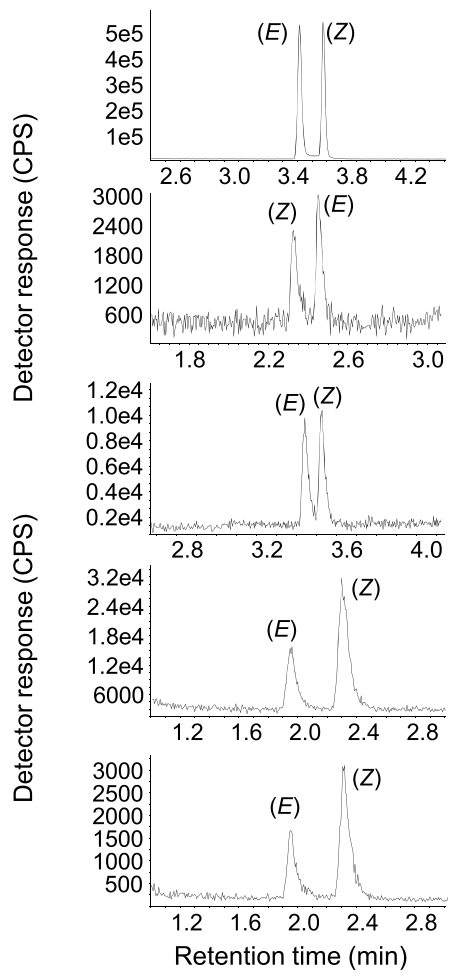

Fig. 4 Biochemical characterization of Erythroxylum fischeri CYP79D60 and CYP79D61. The genes were heterologously expressed in Saccharomyces cerevisae and microsome preparations containing the recombinant proteins were incubated with the potential amino acid substrates L-Phe, L-Tyr, L-Trp, L-Leu, and L-lle. The names of the respective reaction products are listed sequentially next to their LC-MS/MS traces

as Eloria noyesi and Eucleodora cocae, two caterpillar pests, or the leaf cutting ant Acromyrmex spp. [32].

Using homology-based searches, four genes with similarity to $C Y P 79 \mathrm{~s}$ from other plants could be identified in E. coca and E. fischeri. CYP79D60 and CYP79D61 from E. fischeri and CYP79D62 from E. coca were significantly upregulated after JA treatment (Fig. 4) and the encoded enzymes had broad substrate specificity (Figs. 2 and 3). The kinetic parameters of CYP79D60 and CYP79D62 were in the range reported for those of previously characterized poplar CYP79 enzymes [11]. Although the
$K_{\mathrm{m}}$ values were relatively high, it has been suggested that the low substrate affinity of CYP79 enzymes has evolved to avoid possible depletion of free amino acid pools in plants [19]. Considering both the $K_{\mathrm{m}}$ and maximal velocity values for the conversion of the different substrates (Table 2), it is likely that CYP79D60 and CYP79D62 accept L-phenylalanine, L-leucine, L-isoleucine, and L-tryptophan as substrates in planta. Moreover, the accumulation and emission of their aldoxime products after JA treatment (Table 1; Fig. 5) coupled with the JA-induced expression of their genes (Fig. 4) indicate that CYP79D62

Table 2 Kinetic parameters for CYP79D60, CYP79D62, and CYP79D63. The maximal velocities were measured in the presence of 1 mM substrate. CYP79D63 showed no activity with L-Phe, L-Leu, L-Ile, and L-Tyr

\begin{tabular}{|c|c|c|c|c|c|c|}
\hline \multirow[b]{2}{*}{ substrate } & \multicolumn{2}{|l|}{ CYP79D60 } & \multicolumn{2}{|l|}{ CYP79D62 } & \multicolumn{2}{|l|}{ CYP79D63 } \\
\hline & $\begin{array}{l}K_{\mathrm{m}} \\
(\mathrm{mM})\end{array}$ & $\begin{array}{l}\text { Maximal velocity } \\
\left(\mathrm{ng}^{*} \mathrm{~h}^{-1} \text { assay }^{-1}\right)\end{array}$ & $\begin{array}{l}K_{\mathrm{m}} \\
(\mathrm{mM})\end{array}$ & $\begin{array}{l}\text { Maximal velocity } \\
\left(\mathrm{ng}^{*} h^{-1 *} \text { assay }^{-1}\right)\end{array}$ & $\begin{array}{l}K_{\mathrm{m}} \\
(\mathrm{mM})\end{array}$ & $\begin{array}{l}\text { Maximal velocity } \\
\left(\mathrm{ng}^{*} \mathrm{~h}^{-1 *} \text { assay }^{-1}\right)\end{array}$ \\
\hline L-Phe & $0.58 \pm 0.05$ & $160.44 \pm 4.33$ & $0.67 \pm 0.07$ & $424.00 \pm 15.24$ & - & - \\
\hline L-Leu & $0.23 \pm 0.08$ & $68.58 \pm 2.49$ & $0.59 \pm 0.08$ & $256.90 \pm 7.45$ & - & - \\
\hline L-lle & $1.28 \pm 0.25$ & $32.62 \pm 5.16$ & $3.27 \pm 0.42$ & $42.55 \pm 3.49$ & - & - \\
\hline L-Trp & $2.74 \pm 0.11$ & $26.50 \pm 0.32$ & $1.09 \pm 0.04$ & $16.36 \pm 0.31$ & $0.48 \pm 0.05$ & $2.92 \pm 0.14$ \\
\hline L-Tyr & $6.09 \pm 1.32$ & $4.66 \pm 0.43$ & $4.99 \pm 0.46$ & $73.18 \pm 1.93$ & - & - \\
\hline
\end{tabular}



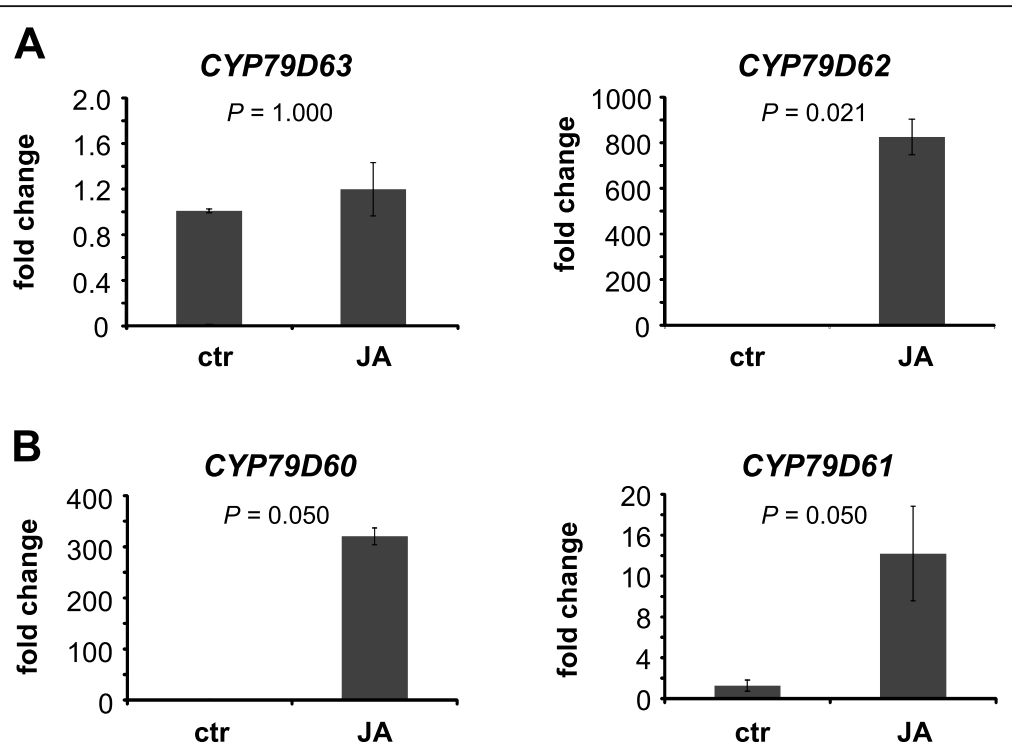

Fig. 5 Trancript abundance of CYP79D genes in jasmonic acid-treated and untreated control leaves of Erythroxylum coca (a) and E. fischeri (b). Twigs were cut and placed in either tap water (ctr) or jasmonic acid $(200 \mu \mathrm{M})$ for $18 \mathrm{~h}$. Gene expression was determined by qRT-PCR. Means and standard errors are shown ( $E$. coca, $n=4 ; E$. fischeri, $n=3$ ). The Kruskal-Wallis rank sum test was used to test for statistical significance. $P$-values $\leq$ 0.05 indicate significant difference between the treatments. ctr, control treatment; JA, jasmonic acid treatment

and CYP79D60 contribute to herbivore-induced aldoxime formation in E. coca and E. fischeri, respectively. The JA-induced production of aldoximes might be further promoted by the increased accumulation of the respective amino acid substrates in JA-treated leaves (Additional file 1: Table S1). Since CYP79D60 and CYP79D61 are highly similar to each other (93\% amino acid identity; Fig. 1) and showed no remarkable differences in in vitro assays (Fig. 3), the kinetic parameters of CYP79D61 were not determined in this study. Although it is likely that
CYP79D61 has similar kinetic constants to CYP79D60, the lower expression level of CYP79D61 in JA-treated leaves in comparison to CYP79D60 suggests only a minor role for this enzyme in aldoxime production in E. fischeri.

While CYP79D60, CYP79D61, and CYP79D62 are likely involved in plant defense, the biological function of CYP79D63 remains unclear. In contrast to the other three enzymes, CYP79D63 accepted exclusively Ltryptophan as substrate (Fig. 2). The affinity of CYP79D63
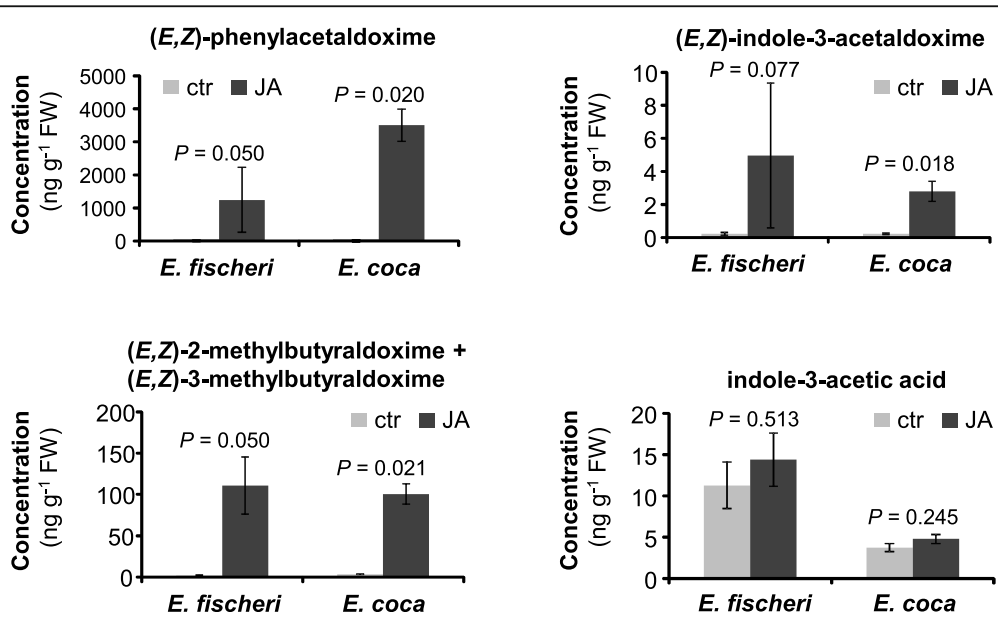

Fig. 6 The accumulation of different aldoximes and indole-3-acetic acid (IAA) in jasmonic acid-treated and untreated control leaves of Erythroxylum coca and E. fischeri. Twigs were cut and placed in either tap water (ctr) or jasmonic acid ( $200 \mu \mathrm{M})$ for $18 \mathrm{~h}$. Aldoximes and IAA were extracted with methanol and analyzed using LC-MS/MS. Means and standard errors are shown ( $E$. coca, $n=4$; $E$. fischeri, $n=3$ ). The Kruskal-Wallis rank sum test was used to test for statistical significance. P-values $\leq 0.05$ indicate significant difference between the treatments. ctr, control treatment; JA, jasmonic acid treatment 
for L-tryptophan was higher in comparison to CYP79D60, CYP79D61, and CYP79D62 (Table 2); however, the low relative product formation indicates a low turnover number for this enzyme. Since gene expression was not influenced by JA treatment, it is unlikely that CYP79D63 contributes to herbivore-induced accumulation of $(E, Z)$ indole-3-acetaldoxime. In many plants, the conversion of $(E, Z)$-indole-3-acetaldoxime into the corresponding acid is thought to serve as an alternative route for the formation of auxin [33-36] and thus it is conceivable that CYP79D63 might produce (E,Z)-indole-3-acetaldoxime as precursor for constitutive auxin formation in leaves or other growing plant parts of $E$. coca. A comprehensive correlation between CYP79D63 gene expression and the accumulation of auxin in different plant organs and different developmental stages might help to elucidate the potential role of CYP79D63 in auxin formation.

As a result of domestication, many crop plants show altered levels of secondary compounds in comparison to their wild relatives [37]. E. coca, for example, has been cultivated for thousands of years and has been selected for high-level production of the pharmacologically active tropane alkaloid cocaine [38]. The cultivated species contains 20-100 times more cocaine in its leaves then closely related wild species [39]. While such selection for high-level production of useful compounds or for lowlevel production of undesired compounds is controlled by the breeder, domestication can also have unrecognized and unwanted side effects. The accumulation of an inactive allele of $(E)$ - $\beta$-caryophyllene synthase during breeding of North American maize, for instance, led to the loss of $(E)$ - $\beta$-caryophyllene production in most of these lines [40]. (E)- $\beta$-Caryophyllene is usually released as volatile from herbivore-damaged maize leaves and roots and has been shown to be involved in different indirect defence reactions above and below ground [40-43]. In this study we showed that E. coca and E. fischeri accumulate and release the same aldoximes, nitriles, and nitro compounds after JA-treatment in comparable amounts, suggesting that domestication did not alter these plant defence responses in cultivated E. coca. Whether the quantitative differences between other single compounds in the JA-induced volatile bouquets of $E$. coca and E. fischeri are species specific or are the result of the breeding of $E$. coca, is still unclear.

\section{Conclusions}

Herbivore-induced volatile blends are in general very complex and contain dozens of substances. However, the enzymatic machinery behind this complexity is often astonishingly simple, comprising only a handful of enzymes with broad substrate and/or product specificity. Terpene synthases, the key enzymes in terpene biosynthesis, for instance, can produce mixtures of up to
50 compounds from one substrate [44]. Moreover, methyltransferases and acyltransferases involved in the formation of volatile esters have been reported to accept multiple substrates [31, 45, 46]. Such promiscuity in the substrate and/or product specificity of volatileproducing enzymes seems to be a general phenomenon that allows plants to efficiently produce a large mixture of different volatiles with only a limited number of enzymes. Mixtures may have specific advantages in plant defense [47]. Recently we showed that two poplar CYP79s involved in volatile aldoxime formation also exhibit broad substrate specificity in contrast to all other previously described CYP79s [11]. The Erythroxylum enzymes characterized in this study represent the second example for CYP79s having broad substrate specificity and it is thus tempting to speculate that such promiscuity might be a general feature for CYP79s forming herbivore-induced volatiles. However, further research on volatile aldoxime-producing CYP79 enzymes from diverse plant families is still needed to substantiate this assertion and to understand the evolutionary and structural causes of broad substrate specificity in this enzyme class.

\section{Methods}

\section{Plant material and plant treatment}

Seeds of Erythroxylum coca var coca were obtained from the botanical garden Bonn, Germany, and were germinated in sterilized potting soil. Live plants of E. fischeri were collected in Kenya and shipped to the MPICE. Plants were grown in a growth chamber set at $22{ }^{\circ} \mathrm{C}$ under a 12 $\mathrm{h} / 12 \mathrm{~h}$ light/dark cycle, with humidity of $65 \%$ and $70 \%$, respectively, and were fertilized once a week with Ferty 3 (15-10-15) and Wuxal Top N (Planta Düngemittel, Regenstauf, Germany). The cultivation of E. coca was authorized by the Bundesinstitut für Arzneimittel und Medizinprodukte (BfArM) (permit number, BtM 4515971).

For jasmonic acid (JA) treatment, JA $(100 \mathrm{mg} / \mathrm{ml}$ ethanol) was diluted in tap water to a final concentration of $200 \mu \mathrm{M}$. Ethanol was diluted in tap water in the same way and used as control. From each E. coca plant $(n=4)$, four twigs of about $15-20 \mathrm{~cm}$ in length were cut and immediately placed in glass beakers containing either JA (two twigs) or control solution (the other two twigs). For E. fischeri, two twigs of about $20 \mathrm{~cm}$ in length were cut from each plant $(n=3)$ and only one twig was used per treatment. Twigs were left in JA or control solution overnight for $18 \mathrm{~h}$ before the volatile collection.

\section{Volatile collection and analysis}

Volatile collections were performed in a growth chamber under conditions as described above. Glass beakers containing the Erythroxylum twigs were separately placed in 31 glass desiccators which were tightly closed. Purified air pumped into the desiccator at a rate of $0.51 \mathrm{~min}^{-1}$ 
came into contact with the plant and left the vessel through a filter packed with $30 \mathrm{mg}$ Super-Q (ARS, Inc., Gainesville, FL, USA). Volatiles were collected for $5 \mathrm{~h}(9 \mathrm{am}-2 \mathrm{pm})$. After the collection, the plant material was immediately frozen in liquid nitrogen for further analysis. The volatile compounds were desorbed from the filters by eluting the filter twice with $100 \mu \mathrm{l}$ dichloromethane containing nonyl acetate as an internal standard $\left(10 \mathrm{ng}^{-1} \mathrm{l}^{-1}\right)$.

Qualitative and quantitative volatile analysis was conducted using an Agilent 6890 Series gas chromatograph (Agilent Technologies GmbH, Waldbronn, Germany) coupled to an Agilent 5973 quadrupole mass selective detector (interface temp, $270{ }^{\circ} \mathrm{C}$; quadrupole temp, $150^{\circ}$ $\mathrm{C}$; source temp, $230{ }^{\circ} \mathrm{C}$; electron energy, $70 \mathrm{eV}$ ) or a flame ionization detector (FID) operated at $300{ }^{\circ} \mathrm{C}$, respectively. The constituents of the volatile bouquet were separated using a ZB-WAX column (Phenomenex, Aschaffenburg, Germany, $60 \mathrm{~m} \times 0.25 \mathrm{~mm} \times$ $0.15 \mu \mathrm{m})$ and $\mathrm{He}$ (MS) or $\mathrm{H}_{2}$ (FID) as carrier gas. The sample $(1 \mu \mathrm{L})$ was injected without split at an initial oven temperature of $40{ }^{\circ} \mathrm{C}$. The temperature was held for $2 \mathrm{~min}$ and then increased to $225^{\circ} \mathrm{C}$ with a gradient of $5{ }^{\circ} \mathrm{C} \mathrm{min}^{-1}$, held for another $2 \mathrm{~min}$, and then further increased to $250{ }^{\circ} \mathrm{C}$ with $100{ }^{\circ} \mathrm{C} \min ^{-1}$ and a hold for $1 \mathrm{~min}$.

Compounds were identified by comparison of retention times and mass spectra to those of authentic standards obtained from Fluka (Seelze, Germany), Roth (Karlsruhe, Germany), Sigma (St. Louis, MO, USA), and Bedoukian (Danbury, CT, USA) or by reference spectra in the Wiley and National Institute of Standards and Technology libraries. The absolute amount of all compounds was determined based on their FID peak area in relation to the area of the internal standard.

\section{Plant tissue sampling, RNA extraction, and reverse transcription}

Erythroxylum leaf material was harvested immediately after the volatile collection, flash-frozen with liquid nitrogen, and stored at $-80{ }^{\circ} \mathrm{C}$ until further processing. After grinding the frozen leaf material in liquid nitrogen to a fine powder, total RNA was isolated using an InviTrap Spin Plant RNA kit (Stratec, Berlin, Germany) according to manufacturer's instructions. RNA concentration, purity, and quality were assessed using a spectrophotometer (NanoDrop 2000c, Thermo Scientific, Wilmington, DE, USA) and an Agilent 2100 Bioanalyzer. RNA was treated with TurboDNase (ThermoFisher Scientific, https://www.thermofisher. com) prior to cDNA synthesis. Single-stranded cDNA was prepared from $1 \mu \mathrm{g}$ of DNase-treated RNA using
SuperScript ${ }^{\mathrm{TM}}$ III reverse transcriptase and oligo ( $\left.\mathrm{dT}_{12-18}\right)$ primers (Invitrogen, Carlsbad, CA, USA).

\section{Identification and heterologous expression of CYP79 genes}

A TBLASTN search against an in-house 454 cDNA sequencing database of $E$. coca young leaf tissue with CYP79D6v3 from Populus trichocarpa (GenBank AHF20912.1) as input sequence revealed one sequence with similarity to plant CYP79s. The full-length gene was designated as CYP79D62 according to the general P450 nomenclature (D.R. Nelson, P450 Nomenclature Committee) and could be amplified from cDNA attained from JA-treated leaves of E. coca. The PCR product was cloned into the sequencing vector $\mathrm{pCR}^{\circ}$-Blunt II-TOPO (Invitrogen) and both strands were fully sequenced using the Sanger method. Sequencing of several clones revealed a second CYP79 gene that was designated as CYP79D63. Using the primers designed for amplification of E. coca CYP79 genes, a CYP79 sequence could be amplified from cDNA made from JA-treated E. fischeri leaves (CYP79D60). To identify further potential CYP79D candidates, primers specific to conserved regions among the obtained genes were designed and PCR was performed with cDNA made from JA-treated Erythroxylum leaves. While most of the resulting amplicons were identical to CYP79D62, CYP79D63, and CYP79D60, one fragment amplified from E. fischeri cDNA showed sequence divergence. RacePCR was performed to obtain the full-length clone, which was designated as CYP79D61. Primer sequence information is given in Additional file 1: Table S4.

For heterologous expression in Saccharomyces cerevisiae, the complete open reading frames of CYP79D62, CYP79D63, CYP79D61, and CYP79D60 were cloned into the pESC-Leu2d vector [48] as NotI/SacI fragments. The resulting constructs were transferred into the $S$. cerevisiae strain WAT11 [49] and single yeast colonies were picked to inoculate starting cultures containing $30 \mathrm{~mL}$ SC minimal medium lacking leucine $\left(6.7 \mathrm{~g} \mathrm{~L}^{-1}\right.$ yeast nitrogen base without amino acids, but with ammonium sulfate). Other components: $100 \mathrm{mg} \mathrm{L}^{-1}$ of L-adenine, Larginine, L-cysteine, L-lysine, L-threonine, L-tryptophan and uracil; $50 \mathrm{mg} \mathrm{L}^{-1}$ of the amino acids L-aspartic acid, L-histidine, L-isoleucine, L-methionine, L-phenylalanine, L-proline, L-serine, L-tyrosine, L-valine; $20 \mathrm{~g} \mathrm{~L}^{-1} \mathrm{D}$ glucose. The cultures were grown overnight at $28{ }^{\circ} \mathrm{C}$ and $180 \mathrm{rpm}$. One OD of the starting cultures (approx. $2 \times$ $10^{7}$ cells $\mathrm{mL}^{-1}$ ) was used to inoculate $100 \mathrm{~mL}$ YPGA full medium cultures $\left(10 \mathrm{~g} \mathrm{~L}^{-1}\right.$ yeast extract, $20 \mathrm{~g} \mathrm{~L}^{-1}$ bactopeptone, $74 \mathrm{mg} \mathrm{L}^{-1}$ adenine hemisulfate, $20 \mathrm{~g} \mathrm{~L}^{-1} \mathrm{D}$ glucose) which were grown for 32-35 h (until OD about 5 ), induced by the addition of galactose and cultured for another 15-18 h. The cultures were centrifuged (7500g, 
$10 \mathrm{~min}, 4^{\circ} \mathrm{C}$ ), the supernatant was decanted, and the cell pellets were resuspended in $30 \mathrm{~mL}$ TEK buffer $(50 \mathrm{mM}$ Tris- $\mathrm{HCl} \mathrm{pH} \mathrm{7.5,} 1 \mathrm{mM}$ EDTA, $100 \mathrm{mM} \mathrm{KCl}$ ) and centrifuged again. Then, the pellets were carefully resuspended in $2 \mathrm{~mL}$ of TES buffer $(50 \mathrm{mM}$ Tris- $\mathrm{HCl} \mathrm{pH} \mathrm{7.5,} 1$ mM EDTA, $600 \mathrm{mM}$ sorbitol, $10 \mathrm{~g} \mathrm{~L}^{-1}$ bovine serum fraction $\mathrm{V}$ protein and $1.5 \mathrm{mM} \beta$-mercaptoethanol) and transferred to a $50 \mathrm{~mL}$ conical tube. Glass beads $(0.45-$ $0.50 \mathrm{~mm}$ diameter, Sigma-Aldrich Chemicals, Steinheim, Germany) were added so that they filled the full volume of the cell suspension. Yeast cell walls were disrupted by 5 cycles of 1 min shaking by hand and subsequent cooling down on ice for $1 \mathrm{~min}$. The crude extracts were recovered by washing the glass beads 4 times with $5 \mathrm{~mL}$ TES. The combined washing fractions were centrifuged $(7500 \mathrm{~g}, 10$ $\min , 4^{\circ} \mathrm{C}$ ), and the supernatant was transferred to another tube and centrifuged again $\left(100,000 \mathrm{~g}, 60 \mathrm{~min}, 4^{\circ} \mathrm{C}\right)$. The resulting microsomal protein fractions were homogenized in $2 \mathrm{~mL}$ TEG buffer (50 mM Tris- $\mathrm{HCl}, 1 \mathrm{mM}$ EDTA, 30 $\% \mathrm{w} / \mathrm{v}$ glycerol) using a glass homogenizer (Potter-Elvehjem, Fisher Scientific, Schwerte, Germany). Aliquots were stored at $-20{ }^{\circ} \mathrm{C}$.

\section{Analysis of recombinant CYP79}

To determine the substrate specificity of Erythroxylum CYP79 enzymes, yeast microsomes harboring recombinant protein were incubated for $30 \mathrm{~min}$ at $25^{\circ} \mathrm{C}$ and 300 rpm individually with the potential substrates L-Phe, LVal, L-Leu, L-Ile, L-Tyr, and L-Trp in glass vials containing $300 \mu \mathrm{L}$ of the reaction mixture $(75 \mathrm{mM}$ sodium phosphate buffer ( $\mathrm{pH} 7.0$ ), $1 \mathrm{mM}$ substrate (concentration was variable for $\mathrm{K}_{m}$ determination), $1 \mathrm{mM} \mathrm{NADPH}$, and $10 \mu \mathrm{L}$ of the prepared microsomes). Reaction products were analyzed using LC-MS/MS as described below.

For the determination of the $\mathrm{K}_{m}$ values, assays were carried out in triplicate and stopped by placing the samples on ice after $300 \mu \mathrm{L} \mathrm{MeOH}$ were added. Enzyme concentrations and incubation times were chosen so that the reaction velocity was linear during the incubation time period.

\section{qRT-PCR analysis}

CDNA was prepared as described above and diluted 1:10 with water. For the amplification of CYP79D gene fragments with a length of about $100-150 \mathrm{bp}$, primer pairs were designed having a $\operatorname{Tm} \geq 60{ }^{\circ} \mathrm{C}$, a GC content between $40-55 \%$, and a primer length in the range of 20-25 nt (see Additional file 1: Table S4 for primer information). Primer specificity was confirmed by agarose gel electrophoresis, melting curve analysis, and standard curve analysis and by sequence verification of cloned PCR amplicons. Primer pair efficiency was determined using the standard curve method with fivefold serial dilution of cDNA and was found to be between 97 and
$104 \%$. Samples were run in triplicate using the Brilliant III SYBR Green QPCR Master Mix (Stratagene, Carlsbad, CA, USA). The following PCR conditions were applied for all reactions: Initial incubation at $95{ }^{\circ} \mathrm{C}$ for 3 min followed by 40 cycles of amplification $\left(95^{\circ} \mathrm{C}\right.$ for $5 \mathrm{~s}$, $60{ }^{\circ} \mathrm{C}$ for $\left.10 \mathrm{~s}\right)$. Plate reads were taken during the annealing and the extension steps of each cycle. Data for the melting curves were recorded at the end of cycling from $60{ }^{\circ} \mathrm{C}$ to $95^{\circ} \mathrm{C}$.

All samples were run on the same PCR machine (Bio-Rad CFX Manager 3.1, Bio-Rad Laboratory, Hercules, CA, USA) in an optical 96-well plate. Three (E. fischeri) or four (E. coca) biological replicates were analyzed as triplicates in the qRT-PCR for each of the three treatments.

\section{LC-MS/MS analysis of aldoximes, amino acids, and auxin}

For determining amino acid and aldoxime concentration, $100 \mathrm{mg}$ of plant powder was extracted with $1 \mathrm{~mL}$ $\mathrm{MeOH}$. For the measurement of amino acids, the $\mathrm{MeOH}$ extract was diluted 1:10 with water and spiked with ${ }^{13} \mathrm{C}$, ${ }^{15} \mathrm{~N}$ labeled amino acids (algal amino acids ${ }^{13} \mathrm{C},{ }^{15} \mathrm{~N}$, Isotec, Miamisburg, $\mathrm{OH}, \mathrm{USA}$ ) at a concentration of $10 \mu \mathrm{g}$ of the mix per mL. Amino acids in the diluted $\mathrm{MeOH}$ extract were directly analyzed by LC-MS/MS as recently described [11].

Aldoximes were measured from $\mathrm{MeOH}$ extracts using an Agilent 1200 HPLC system coupled to an API 5000 tandem mass spectrometer (Applied Biosystems, Darmstadt, Germany). Formic acid (0.2 \%) in water and acetonitrile were employed as mobile phases $A$ and $B$, respectively, on a Zorbax Eclipse XDB-C18 column $(50 \times 4.6 \mathrm{~mm}, 1.8 \mu \mathrm{m}$, Agilent Technologies). The elution profile was: 0-4 min, 10$70 \% \mathrm{~B} ; 4-4.1 \mathrm{~min}, 70-100 \% \mathrm{~B} ; 4.1-5 \min 100 \% \mathrm{~B}$ and $5.1-7 \mathrm{~min} 10 \% \mathrm{~B}$ at a flow rate of $1.1 \mathrm{~mL} \mathrm{\textrm {min } ^ { - }}$ 1 . The API 5000 tandem mass spectrometer was operated in positive ionization mode (ionspray voltage, $5500 \mathrm{eV}$; turbo gas temp, $700{ }^{\circ} \mathrm{C}$; nebulizing gas, 60 psi; curtain gas, 30 psi; heating gas, 50 psi; collision gas, 6 psi). MRM was used to monitor precursor ion $\rightarrow$ product ion reactions for each analyte as follows: $m / z \quad 136.0 \rightarrow 119.0$ (collision energy (CE), $17 \mathrm{~V}$; declustering potential (DP), $56 \mathrm{~V})$ for phenylacetaldoxime; $m / z \quad 102.0 \rightarrow 69.0(\mathrm{CE}, 13 \mathrm{~V}$; DP, $31 \mathrm{~V}$ ) for 2methylbutyraldoxime; $m / z \quad 102.0 \rightarrow 46.0 \quad(\mathrm{CE}, 15 \mathrm{~V}$; DP, $31 \mathrm{~V})$ for 3-methylbutyraldoxime; $\mathrm{m} / \mathrm{z} 175.0 \rightarrow$ 158.0 (CE, $17 \mathrm{~V}$; DP, $56 \mathrm{~V}$ ) for indole-3-acetaldoxime and $m / z \quad 152.0 \rightarrow 107.0(\mathrm{CE}, 27 \mathrm{~V}$; DP, $100 \mathrm{~V})$ for $p$-hydroxyphenylacetaldoxime. The concentration of aldoximes was determined using external standard curves made with authentic standards synthesized as described in the literature [11]. 
Indole-3-acetic acid (IAA) was analyzed as follows: $100 \mathrm{mg}$ of plant powder were extracted with $300 \mu \mathrm{L}$ $\mathrm{MeOH}$, and $200 \mu \mathrm{L}$ of the extract was diluted 1:10 with water containing $0.1 \%$ formic acid and loaded onto equilibrated $\mathrm{Chromabond}^{\circ} \mathrm{HR}-\mathrm{X}$ polypropylene columns (45 $\mu \mathrm{m}$, Macherey Nagel, Düren, Germany). The columns were washed with acidified water. The fraction containing the auxins was eluted with $1 \mathrm{~mL}$ acetonitrile, which was then dried under a stream of nitrogen gas. The samples were redissolved in $30 \mu \mathrm{L} \mathrm{MeOH}$ and subsequently analyzed by the same LC-MS/MS system as described above. Separations were performed on an Agilent XDB-C18 column $(50 \mathrm{~mm} \times 4.6,1.8 \mu \mathrm{m})$. Eluents A and B were water containing $0.05 \%$ formic acid and acetonitrile, respectively. The elution profile was: $0-0.5 \mathrm{~min}, 5 \% \mathrm{~B}$ in A; $0.5-4.0 \mathrm{~min}$, 5-50 \% B; 4.1-4.5 min $100 \%$ B and 4.6-7 min $5 \%$ B. The flow rate was set to $1.1 \mathrm{~mL} \mathrm{~min}^{-1}$. The API 5000 tandem mass spectrometer was operated in positive ionization mode (ion spray voltage, $5500 \mathrm{eV}$; turbo gas temp, $700{ }^{\circ} \mathrm{C}$; nebulizing gas, 60 psi; curtain gas, 30 psi; heating gas, 50 psi; collision gas, $6 \mathrm{psi})$. The MRM transition and parameter settings for IAA were as follows: $m / z 176 \rightarrow 130$ (CE, $19 \mathrm{~V}$; DP, $31 \mathrm{~V})$. IAA concentration was determined by spiking the plant extracts with known amounts of ${ }^{2} \mathrm{H}_{5}$-IAA (OlChemIm Ltd., Olomouc, Czech Republic).

\section{Sequence analysis and phylogenetic tree construction}

An alignment of Erythroxylum CYP79 genes and characterized CYP79 genes from other plants was constructed using the MUSCLE (codon) algorithm (gap open, -2.9; gap extend, 0; hydrophobicity multiplier, 1.5; clustering method, upgmb) implemented in MEGA6 [50]. Based on the translated MUSCLE codon alignment, a tree was reconstructed with MEGA6 using a neighbor joining algorithm (model/method, JTT model; substitutions type, amino acids; rates among sites, uniform rates; gaps/missing data treatment, partial deletion; site coverage cutoff, $80 \%$ ). A bootstrap resampling analysis with 1000 replicates was performed to evaluate the tree topology.

\section{Statistical analysis}

Differences in gene expression, volatile emission, and the accumulation of aldoximes, auxin, and amino acids between jasmonic acid-induced and untreated control plants were analyzed with Kruskal-Wallis rank sum tests for E. coca and E. fischeri separately in R version 3.1.1 [51].

\section{Accession numbers}

Sequence data for genes in this article can be found in the GenBank under the following identifiers: CYP79D60 (KX344462), CYP79D61 (KX344460), CYP79D62 (KX344463), CYP79D63 (KX344461).

\section{Additional file}

Additional file 1: Table S1. Expression levels of potential housekeeping genes in jasmonic acid-treated (JA) and untreated control (ctr) leaves of Erythroxylum fischeri. Table S2. Expression levels of potential house-keeping genes in jasmonic acid-treated (JA) and untreated control (ctr) leaves of Erythroxylum coca. Table S3. Amino acid concentrations in untreated (control) and jasmonic acid-treated (JA treatment) leaves of Erythroxylum coca and E. fischeri. Table S4. Oligonucleotides used for isolation and qRT-PCR analysis of Erythroxylum coca and E. fischeri CYP79D genes. (DOCX $38 \mathrm{~kb}$ )

\section{Abbreviations}

CYP: Cytochrome P450 monooxygenase; GLV: Green leaf volatile; JA: Jasmonic acid; qRT-PCR: Quantitative real-time PCR; DMNT: (3E)-4,8dimethylnona-1,3,7-triene; TMTT: (3E,7E)-4,8,12-trimethyltrideca-1,3,7,11tetraene

\section{Acknowledgements}

We thank Tamara Krügel and all the MPI-CE gardeners for their help with rearing the Erythroxylum plants. Furthermore, we thank Patrick Chalo Mutiso from the University of Nairobi, Kenya, for collecting and shipping Erythroxylum fischeri plants.

\section{Funding}

The research was funded by the Max-Planck Society.

Availability of data and materials

All supporting data are included as additional files. Constructs described in this work and datasets analysed during the current study are available from the corresponding author upon request. Sequences were deposited in GenBank (see Methods section).

Authors' contributions

JJ, SI, JG, and TGK designed research. KL, JJ, SI, and TGK carried out the experimental work. MH and TGK analysed data. TGK wrote the manuscript. All authors read and approved the final manuscript.

\section{Competing interests}

The authors declare that they have no competing interests.

Consent for publication

Not applicable.

Ethics approval and consent to participate

Not applicable.

\section{Author details}

${ }^{1}$ Max Planck Institute for Chemical Ecology, Hans-Knöll-Strasse 8, D-07745 Jena, Germany. ${ }^{2}$ Present address: Fraunhofer Institute for Molecular Biology and Applied Ecology IME, Forckenbeckstrasse 6, D-52074 Aachen, Germany. ${ }^{3}$ Present address: Michael Smith Laboratories, University of British Columbia, Vancouver, Canada.

Received: 6 August 2016 Accepted: 27 September 2016 Published online: 04 October 2016

\section{References}

1. Unsicker SB, Kunert G, Gershenzon J. Protective perfumes: the role of vegetative volatiles in plant defense against herbivores. Curr Opin Plant Biol. 2009;12(4):479-85.

2. De Moraes CM, Mescher MC, Tumlinson JH. Caterpillar-induced nocturnal plant volatiles repel conspecific females. Nature. 2001;410:577-80.

3. Turlings TCJ, Tumlinson JH, Lewis WJ. Exploitation of herbivore-induced plant odors by host-seeking parasitic wasps. Science. 1990;30:1251-3.

4. Schnee C, Kollner TG, Held M, Turlings TCJ, Gershenzon J, Degenhardt J. The products of a single maize sesquiterpene synthase form a volatile defense signal that attracts natural enemies of maize herbivores. Proc Natl Acad Sci U S A. 2006;103(4):1129-34.

5. Raguso RA. Wake up and smell the roses: The ecology and evolution of floral scent. Annu Rev Ecol Evol Syst. 2008;39:549-69. 
6. Gershenzon J. Plant volatiles carry both public and private messages. Proc Natl Acad Sci U S A. 2007;104(13):5257-8.

7. Danner H, Boeckler GA, Irmisch S, Yuan JS, Chen F, Gershenzon J, Unsicker SB, Kollner TG. Four terpene synthases produce major compounds of the gypsy moth feeding-induced volatile blend of Populus trichocarpa. Phytochemistry. 2011;72(9):897-908.

8. Van Den Boom CEM, Van Beek TA, Posthumus MA, De Groot A, Dicke M Qualitative and quantitative variation among volatile profiles induced by Tetranychus urticae feeding on plants from various families. J Chem Ecol. 2004;30(1):69-89.

9. Degen T, Dillmann C, Marion-Poll F, Turlings TCJ. High genetic variability of herbivore-induced volatile emission within a broad range of maize inbred lines. Plant Physiol. 2004;135(4):1928-38.

10. Dudareva N, Klempien A, Muhlemann JK, Kaplan I. Biosynthesis, function and metabolic engineering of plant volatile organic compounds. New Phytol. 2013;198(1):16-32.

11. Irmisch S, McCormick AC, Boeckler GA, Schmidt A, Reichelt M, Schneider B, Block K, Schnitzler JP, Gershenzon J, Unsicker SB, et al. Two herbivore-induced cytochrome P450 enzymes CYP79D6 and CYP79D7 catalyze the formation of volatile aldoximes involved in poplar defense. Plant Cell. 2013;25(11):4737-54.

12. McCormick AC, Irmisch S, Reinecke A, Boeckler GA, Veit D, Reichelt M, Hansson BS, Gershenzon J, Kollner TG, Unsicker SB. Herbivore-induced volatile emission in black poplar: regulation and role in attracting herbivore enemies. Plant Cell Environ. 2014;37(8):1909-23.

13. Irmisch S, McCormick AC, Gunther J, Schmidt A, Boeckler GA, Gershenzon J, Unsicker SB, Kollner TG. Herbivore-induced poplar cytochrome P450 enzymes of the CYP71 family convert aldoximes to nitriles which repel a generalist caterpillar. Plant J. 2014;80(6):1095-107.

14. Hamberger B, Bak S. Plant P450s as versatile drivers for evolution of speciesspecific chemical diversity. Philos Trans R Soc B-Biol Sci. 2013;368(1612): 20120426

15. Halkier BA, Nielsen HL, Koch B, Moller BL. Purification and characterization of recombinant cytochrome P450(Tyr) expressed at high levels in Escherichia coli. Arch Biochem Biophys. 1995;322(2):369-77.

16. Sibbesen O, Koch B, Halkier BA, Moller BL. Cytochrome P450(Tyr) is a multifunctional heme-thiolate enzyme catalyzing the conversion of L-tyrosine to $p$-hydroxyphenylacetaldehyde oxime in the biosynthesis of the cyanogenic glucoside dhurrin in Sorghum bicolor (L) Moench. J Biol Chem. 1995;270(8):3506-11.

17. Irmisch S. Identification and characterization of CYP79D6v4, a cytochrome P450 enzyme producing aldoximes in black poplar (Populus nigra). Plant Signal Behav. 2013; 8(12):e27640.

18. Koch B, Nielsen VS, Halkier BA, Olsen CE, Moller BL. The biosynthesis of cyanogenic glucosides in seedlings of cassava (Manihot esculenta Crantz). Arch Biochem Biophys. 1992;292(1):141-50.

19. Andersen MD, Busk PK, Svendsen I, Moller BL. Cytochromes P450 from cassava (Manihot esculenta Crantz) catalyzing the first steps in the biosynthesis of the cyanogenic glucosides linamarin and lotaustralin Cloning, functional expression in Pichia pastoris, and substrate specificity of the isolated recombinant enzymes. J Biol Chem. 2000;275(3):1966-75.

20. Wittstock U, Halkier BA. Cytochrome P450 CYP79A2 from Arabidopsis thaliana $\mathrm{L}$. catalyzes the conversion of $\mathrm{L}$-phenylalanine to phenylacetaldoxime in the biosynthesis of benzylglucosinolate. J Biol Chem. 2000;275(19):14659-66.

21. Forslund K, Morant M, Jorgensen B, Olsen CE, Asamizu E, Sato S, Tabata S, Bak S. Biosynthesis of the nitrile glucosides rhodiocyanoside $A$ and $D$ and the cyanogenic glucosides lotaustralin and linamarin in Lotus japonicus. Plant Physiol. 2004;135(1):71-84.

22. Schmelz EA, Alborn HT, Tumlinson JH. The influence of intact-plant and excised-leaf bioassay designs on volicitin- and jasmonic acid-induced sesquiterpene volatile release in Zea mays. Planta. 2001;214(2):171-9.

23. Howe GA, Jander G. Plant immunity to insect herbivores. Ann Rev Plant Biol. 2008;59:41-66

24. Jirschitzka J, Schmidt GW, Reichelt M, Schneider B, Gershenzon J, D'Auria JC. Plant tropane alkaloid biosynthesis evolved independently in the Solanaceae and Erythroxylaceae. Proc Natl Acad Sci U S A. 2012; 109(26):10304-9.

25. Schmidt GW, Jirschitzka J, Porta T, Reichelt M, Luck K, Torre JCP, Dolke F, Varesio E, Hopfgartner G, Gershenzon J, et al. The last step in cocaine biosynthesis is catalyzed by a BAHD acyltransferase. Plant Physiol. 2015;167(1):89-101.
26. Durst F, Nelson DR. Diversity and evolution of plant P450 and P450 reductases. Drug Metabol Drug Interact. 1995;12:189-206.

27. Docimo T, Schmidt GW, Luck K, Delaney SK, D'Auria JC. Selection and validation of reference genes for quantitative gene expression studies in Erythroxylum coca. F1000Research. 2013;2:37.

28. Bari $\mathrm{R}$, Jones J. Role of plant hormones in plant defence responses. Plant Mol Biol. 2009:69(4):473-88.

29. Okada K, Abe H, Arimura G. Jasmonates induce both defense responses and communication in monocotyledonous and dicotyledonous plants. Plant Cell Physiol. 2015;56(1):16-27.

30. Pluskota WE, Qu N, Maitrejean M, Boland W, Baldwin IT. Jasmonates and its mimics differentially elicit systemic defence responses in Nicotiana attenuata. J Exp Bot. 2007:58(15-16):4071-82.

31. Kollner TG, Lenk C, Zhao N, Seidl-Adams I, Gershenzon J, Chen F, Degenhardt J. Herbivore-induced SABATH methyltransferases of maize that methylate anthranilic acid using S-adenosyl-L-methionine. Plant Physiol. 2010;153(4):1795-807.

32. Plowman T, Weil AT. Coca pests and pesticides. J Ethnopharmacol. 1979; 1(3):263-78.

33. Bak S, Feyereisen R. The involvement of two P450 enzymes, CYP83B1 and CYP83A1, in auxin homeostasis and glucosinolate biosynthesis. Plant Physiol. 2001;127(1):108-18.

34. Zhao YD, Hull AK, Gupta NR, Goss KA, Alonso J, Ecker JR, Normanly J, Chory J, Celenza JL. Trp-dependent auxin biosynthesis in Arabidopsis: Involvement of cytochrome P450s CYP79B2 and CYP79B3. Genes Dev. 2002;16(23):3100-12.

35. Sugawara S, Hishiyama S, Jikumaru Y, Hanada A, Nishimura T, Koshiba T, Zhao Y, Kamiya Y, Kasahara H. Biochemical analyses of indole-3acetaldoxime-dependent auxin biosynthesis in Arabidopsis. Proc Natl Acad Sci U S A. 2009:106(13):5430-5.

36. Irmisch S, Zeltner P, Handrick V, Gershenzon J, Kollner TG. The maize cytochrome P450 CYP79A61 produces phenylacetaldoxime and indole-3acetaldoxime in heterologous systems and might contribute to plant defense and auxin formation. BMC Plant Biol. 2015;15:128.

37. Hyams E. Plants in the service of man: 10,000 years of domestication. London: J M Dent; 1971.

38. Dillehay TD, Rossen J, Ugent D, Karathanasis A, Vasquez V, Netherly PJ. Early Holocene coca chewing in northern Peru. Antiquity. 2010;84(326):939-53.

39. Plowman T, Rivier L. Cocaine and cinnamoylcocaine content of Erythroxylum species. Ann Bot. 1983:51(5):641-59.

40. Kollner TG, Held M, Lenk C, Hiltpold I, Turlings TCJ, Gershenzon J, Degenhardt J. A maize ( $E$ )- $\beta$-caryophyllene synthase implicated in indirect defense responses against herbivores is not expressed in most American maize varieties. Plant Cell. 2008;20(2):482-94.

41. Rasmann S, Kollner TG, Degenhardt J, Hiltpold I, Toepfer S, Kuhlmann U, Gershenzon J, Turlings TCJ. Recruitment of entomopathogenic nematodes by insect-damaged maize roots. Nature. 2005;434(7034):732-7.

42. Robert CAM, Erb M, Duployer M, Zwahlen C, Doyen GR, Turlings TCJ. Herbivore-induced plant volatiles mediate host selection by a root herbivore. New Phytol. 2012;194(4):1061-9.

43. Robert CAM, Erb M, Hiltpold I, Hibbard BE, Gaillard MDP, Bilat J, Degenhardt J, Cambet-Petit-Jean X, Turlings TCJ, Zwahlen C. Genetically engineered maize plants reveal distinct costs and benefits of constitutive volatile emissions in the field. Plant Biotechnol J. 2013;11(5):628-39.

44. Degenhardt J, Kollner TG, Gershenzon J. Monoterpene and sesquiterpene synthases and the origin of terpene skeletal diversity in plants. Phytochemistry. 2009;70(15-16):1621-37.

45. Effmert U, Saschenbrecker S, Ross J, Negre F, Fraser CM, Noel JP, Dudareva N Piechulla B. Floral benzenoid carboxyl methyltransferases: From in vitro to in planta function. Phytochemistry. 2005;66(11):1211-30.

46. D'Auria JC. Acyltransferases in plants: a good time to be BAHD. Curr Opin Plant Biol. 2006:9(3):331-40.

47. Gershenzon J, Fontana A, Burow M, Wittstock U, Degenhardt J. Mixtures of plant secondary metabolites: metabolic origins and ecological benefits. In: Iason GR, Dicke M, Hartley SE, editors. Ecology of Plant Secondary Metabolites: From Genes to Global Processes. 2012. p. 56-77.

48. Ro DK, Ouellet M, Paradise EM, Burd H, Eng D, Paddon CJ, Newman JD, Keasling JD. Induction of multiple pleiotropic drug resistance genes in yeast engineered to produce an increased level of anti-malarial drug precursor, artemisinic acid. BMC Biotechnol. 2008:8:83. 
49. Pompon D, Louerat B, Bronine A, Urban P. Yeast expression of animal and plant P450s in optimized redox environments. Methods Enzymol. 1996;272:51-64.

50. Tamura K, Peterson D, Peterson N, Stecher G, Nei M, Kumar S. MEGA5:

Molecular Evolutionary Genetics Analysis Using Maximum Likelihood, Evolutionary Distance, and Maximum Parsimony Methods. Mol Biol Evol. 2011;28(10):2731-9.

51. R Core Team. R: A language and environment for statistical computing. Vienna: R Foundation for Statistical Computing; 2014.

Submit your next manuscript to BioMed Central and we will help you at every step:

- We accept pre-submission inquiries

- Our selector tool helps you to find the most relevant journal

- We provide round the clock customer support

- Convenient online submission

- Thorough peer review

- Inclusion in PubMed and all major indexing services

- Maximum visibility for your research

Submit your manuscript at www.biomedcentral.com/submit
Biomed Central 